\title{
Nitriding and DLC Coating of Aluminum Alloy Using High-Current Pressure-Gradient-Type Plasma Source
}

\section{Akio NISHIMOTO' ${ }^{*}$, Eiji FURUYA ${ }^{2}$ and Kenji KOUSAKA ${ }^{3}$}

\author{
${ }^{1}$ Department of Chemistry and Materials Engineering, Kansai University, Japan \\ ${ }^{2}$ Technical Management Dept., Chugai Ro Co., Ltd., Japan \\ ${ }^{3}$ Heat Treatment Furnace Div., Chugai Ro Co., Ltd., Japan
}

\begin{abstract}
Nitriding of an A5052 aluminum alloy followed by coating with a diamond-like carbon (DLC) film using a pressure-gradient-type plasma source was performed. The plasma source was operated at a low discharge voltage of 60-100 V and a high current of 60-130 A. First, the aluminum alloy was plasma nitrided for $4 \mathrm{~h}$ at $520^{\circ} \mathrm{C}$ under $0.09-1.1 \mathrm{~Pa}$. The DLC film was then coated using acetylene gas with the same apparatus. The Vickers microhardness of the surface nitrided at $0.51 \mathrm{~Pa}$ increased to approximately $305 \mathrm{HV}$ from an initial value of 125 HV for the base material. In addition, glow discharge-optical emission spectrometry (GDOES) revealed that nitrogen was concentrated in the surface region. After the DLC coating, the sample became reddish brown. The GD-OES results indicated that a carbon-rich region was formed at the top surface (DLC film), followed by the formation of a nitrogen-rich region (nitrided layer). Nanoindentation tests revealed that the hardness of the top surface (DLC film) was $10.3 \mathrm{GPa}$. The DLC coating also exhibited good tribological performance in a ball-on-disk wear test, with friction coefficients of approximately 0.17 , which is considered a low value for DLC. In addition, an intermediate AIN layer was deposited on the nitrided layer using the ion-plating method to enhance the adhesion between the DLC film and the substrate. Rockwell indentation measurements revealed good adhesion. Moreover, the addition of another Si-containing DLC intermediate layer was shown to further improve the adhesion between the nitrided layer and DLC film.
\end{abstract}

\section{Keywords}

Pressure-gradient-type plasma source, Diamond like carbon, Plasma nitriding, Aluminum alloy, Surface modification

\section{Introduction}

Aluminum alloys are beneficial for applications that require low weight because their specific gravity is approximately one-third that of steels. How- ever, for improvement of the hardness, abrasion resistance, or low friction characteristics through the addition of a diamond-like-carbon (DLC) film on the surface, aluminum alloys are disadvantaged owing to their poor adhesion $[1,2]$.

*Corresponding author: Akio NISHIMOTO, Department of Chemistry and Materials Engineering, Kansai University, 3-3-35 Yamate-cho, Suita, Osaka 564-8680, Japan

Accepted: March 07, 2020; Published: March 09, 2020

Copyright: (c) 2020 NISHIMOTO A, et al. This is an open-access article distributed under the terms of the Creative Commons Attribution License, which permits unrestricted use, distribution, and reproduction in any medium, provided the original author and source are credited.

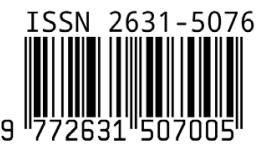

NISHIMOTO et al. Int J Metall Met Phys 2020, 5:048 
To improve the hardness of aluminum alloys by plasma nitriding and to determine whether the poor adhesion of DLC films could be overcome by forming DLC films on a nitrided layer using the plasma chemical vapor deposition (CVD), the authors previously examined the combination of these surface treatments [3]. Improvement of the adhesion properties has also been reported with the addition of a graded AIN film as an intermediate layer on the surface of an aluminum alloys using the unbalanced magnetron sputtering method $[4,5]$.

Nitriding of aluminum alloys is recognized as a difficult technology because the process of nitride formation is inhibited by the oxide layer formed on their surfaces [6-10]. The high-vacuum process for the oxide layer removal of and prevention of re-oxidation is considered key to successful nitriding. The authors previously observed that DLC films can be formed using a pressure-gradient-type plasma source in a high-vacuum area and that hydrogen-less nitriding of an austenitic stainless steel SUS 304 is feasible $[11,12]$. In this study, using the same technique, the A5052 aluminum alloy was subjected to nitriding and then cooled while maintaining the vacuum, and DLC film formation on the top surface was performed. Attempts were also made to improve the adhesion by introducing an AIN film or a Si-containing DLC intermediate layer as the intermediate layer between the nitride layer and the DLC film.

\section{Experimental Details}

\section{Experimental material}

The sample used in this study was a disk material of $\varphi 25 \times 5 \mathrm{~mm}$ of the A5052 Al alloy containing 2.49 mass\% of Mg. The surface to be treated was mirror-polished using electrolytic polishing.

\section{Nitriding and DLC coating equipment}

Figure 1 presents a schematic diagram of the vacuum coating apparatus used in this study. This apparatus was equipped with a pressure-gradient-type plasma source (rated discharge current = 160 A) for plasma generation. A pressure gradient

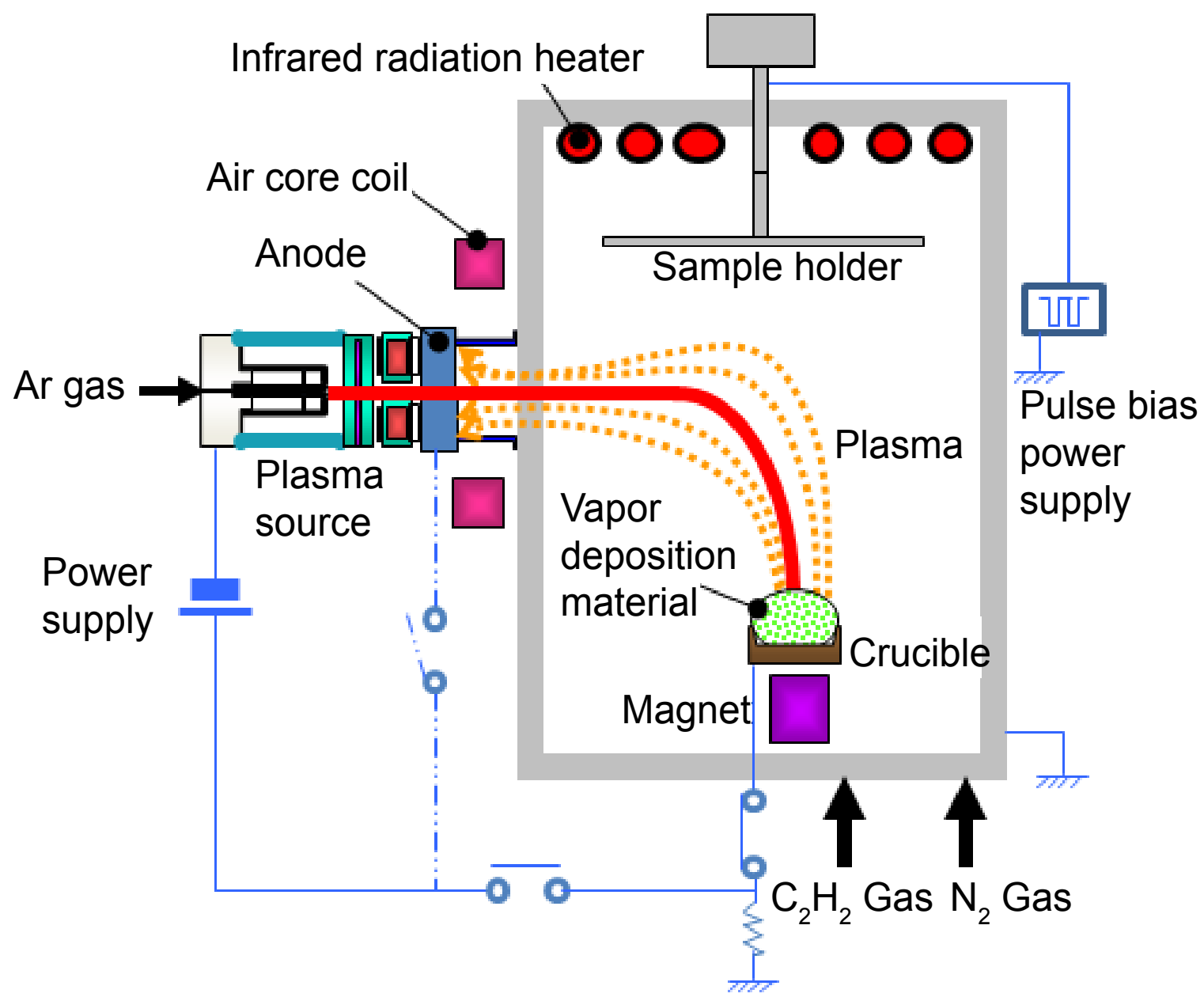

Figure 1: Schematic diagram of plasma treatment apparatus. 

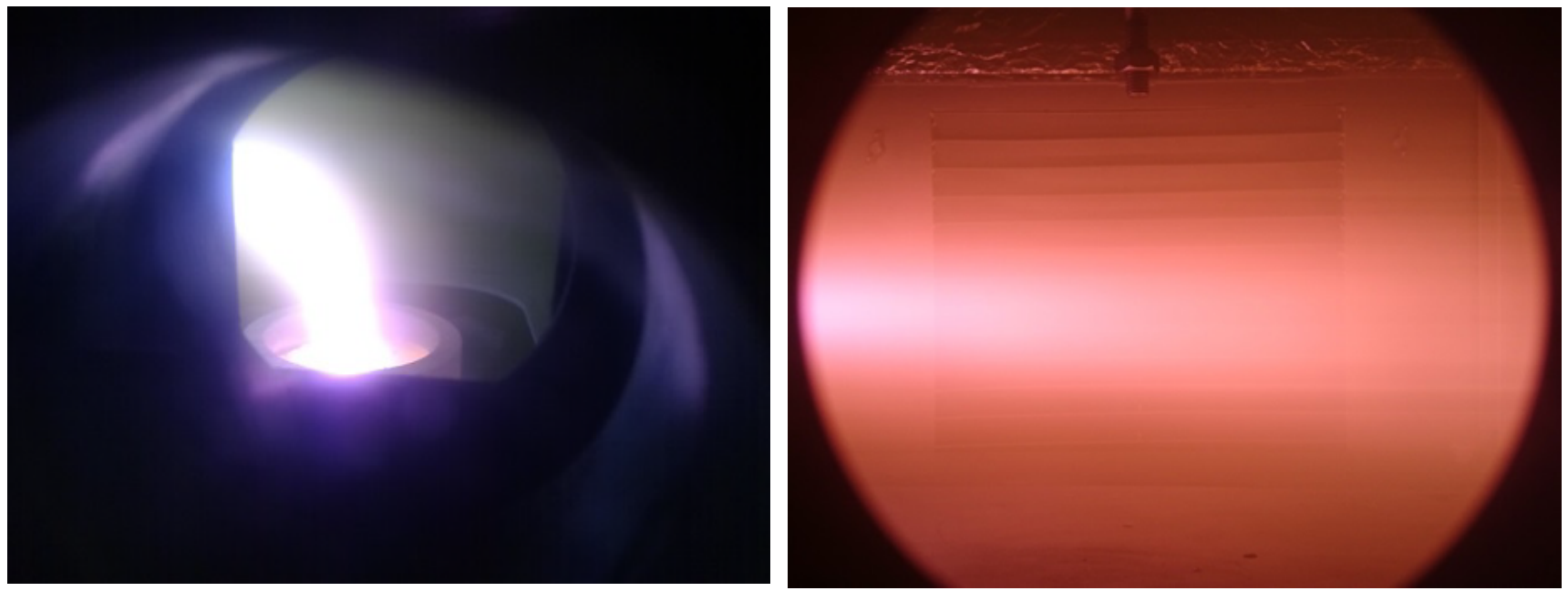

Figure 2: Photographs of plasma bent at a right angle bent plasma and the horizontal plasma.

was generated from the plasma gun toward the inside of the chamber by supplying discharge-assisting Ar gas to the plasma source, and preventing the backflow of ions generated in the chamber, in addition, by introducing reactive gases such as $\mathrm{N}_{2}$ and $\mathrm{C}_{2} \mathrm{H}_{2}$ to the cathode side, damage to the cathode was prevented. The shape of the plasma and the site of irradiation could be easily modified using a combined magnetic field generated by the combination of an air core coil and a magnet [13]. Figure 1 shows an example wherein the plasma is bent at a right angle and irradiated the crucible arranged at the bottom.

The vacuum chamber could be evacuated to a level of $10^{-5} \mathrm{~Pa}$. An infrared heater was installed as the heating source and used to control the temperature of the processed materials. A pulse power source of $5-350 \mathrm{kHz}$ and 0 to $-800 \mathrm{~V}$ was connected to the substrate holder, enabling the application of a pulse bias voltage to the substrate. As described above, the plasma shape could be easily modified, and the plasma could be horizontally discharged. Figure 2 presents photographs of plasma bent at a right angle bent plasma and the horizontal plasma.

\section{Pressure-gradient-type plasma source}

The pressure-gradient-type plasma source, developed by Uramoto [14], enables large direct current (large-DC) discharge using a $\mathrm{LaB}_{6}$ plate cathode. The structure of the plasma gun is shown in Figure 3; the cathode part is a composite of a Ta pipe and a $\mathrm{LaB}_{6}$ plate. Moreover, the hollow cathode discharge is facilitated by supplying discharge-assisting Ar gas from the inside of the cathode. Two grid electrodes are mounted between the cathode and the anode to stabilize the discharge. Plasma generation is possible in the pressure range from the latter half of $10^{-2} \mathrm{~Pa}$ to $1 \mathrm{~Pa}$, and discharge is possible up to $250 \mathrm{~A}$ at $200 \mathrm{~V}$ or less. This plasma source is used for thinfilm production using the reactive ion plating (RIP) [15]. Specifically, a high deposition rate of $14 \mathrm{~nm} / \mathrm{s}$ was achieved for the formation of the $\mathrm{MgO}$ films for plasma displays; furthermore, (110), (200), and (220) crystal orientations were controllable [16].

\section{Nitriding and DLC film coating}

First, heating was performed with the heater on top while exhausting until a vacuum level of $10^{-4} \mathrm{~Pa}$ was attained. Thereafter, plasma was generated by the pressure-gradient-type plasma source, a pulse bias voltage was applied, and Ar bombardment was performed.

Subsequently, a pulse bias voltage of $-150 \mathrm{~V}$ was applied, $500-\mathrm{sccm} \mathrm{N}$ gas at a pressure of $0.51 \mathrm{~Pa}$ was introduced into the chamber, horizontal plasma was generated with a discharge current of $150 \mathrm{~A}$, and hydrogen-less plasma nitriding was performed at a sample temperature of $520^{\circ} \mathrm{C}$ for $360 \mathrm{~min}$. After nitriding and cooling under vacuum, when the temperature was sufficiently lowered, the DLC film with a target thickness of $1.5 \mu \mathrm{m}$ was formed in 29 min under the following conditions: Pressure of $0.21 \mathrm{~Pa}$, discharge current of $60 \mathrm{~A}, \mathrm{C}_{2} \mathrm{H}_{2}$ flow rate of $71 \mathrm{sccm}$, and pulse bias voltage of $-100 \mathrm{~V}$.

\section{Nitriding, AIN intermediate layer, and DLC film coating}

To improve the adhesion between the nitrided 


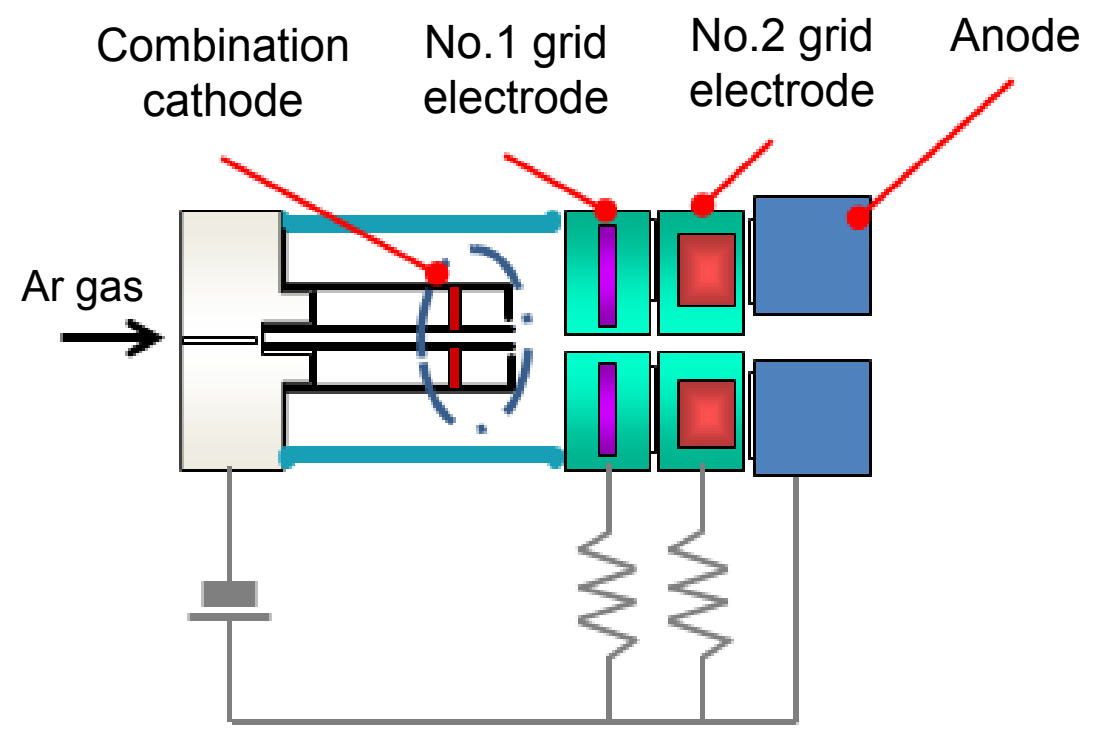

Figure 3: Structure of pressure-gradient-type plasma source.

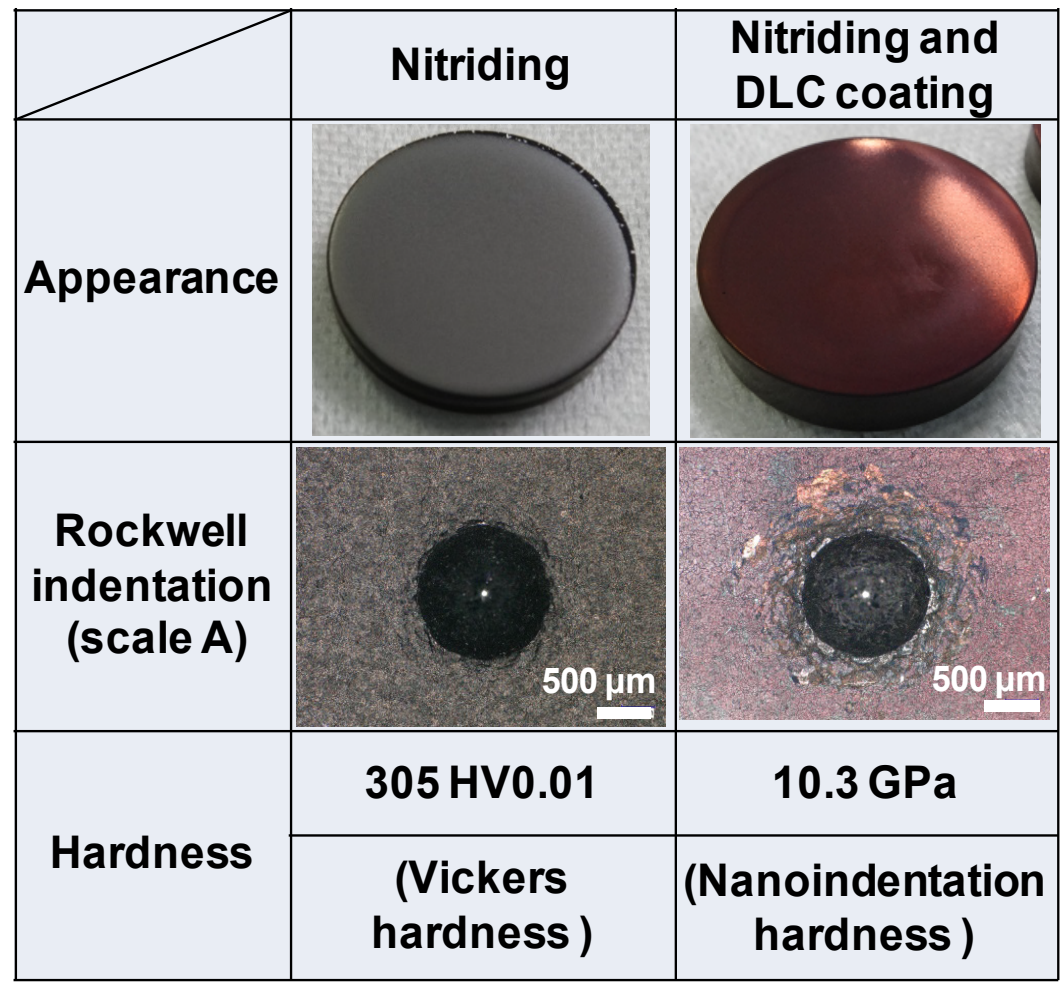

Figure 4: Appearance of samples, Rockwell indentation and surface hardness after nitriding and DLC film coating.

layer and the DLC film, an AIN film was formed as an intermediate layer via RIP. Accordingly, for nitriding of the base material, a thin nitrided layer was formed at a low temperature of $300^{\circ} \mathrm{C}$.

After the Ar bombardment treatment described above plasma nitriding was performed for $60 \mathrm{~min}$ under the following conditions: Treatment pressure of $0.56 \mathrm{~Pa}$, discharge current of $130 \mathrm{~A}, \mathrm{~N}_{2}$ gas flow rate of $500 \mathrm{sccm}$, pulse bias voltage of -150 $\mathrm{V}$, and sample temperature of $300^{\circ} \mathrm{C}$. After nitriding and cooling under vacuum, the discharge circuit was changed and an AIN film was formed using RIP. The target film thickness of AIN was $3.4 \mu \mathrm{m}$, and processing was performed for 55 min under the following conditions: Pressure of $0.22 \mathrm{~Pa}$, discharge output of $8 \mathrm{~kW}$, and $\mathrm{N}_{2}$ flow rate of $300 \mathrm{sccm}$ with- 
out application of a bias voltage. The crucible was filled pure aluminum (purity 99.99\%, particle size 2-5 $\mathrm{mm}$ ) as the vapor deposition material, which was evaporated. After completion of the AIN film formation, the film was cooled again under vacuum; after changing the discharge circuit, DLC film coating was performed for $140 \mathrm{~min}$ at $0.22 \mathrm{~Pa}$, with a discharge current of $60 \mathrm{~A}, \mathrm{C}_{2} \mathrm{H}_{2}$ flow rate of 71 sccm, and pulse bias voltage of $-100 \mathrm{~V}$.

\section{Nitriding, AIN and Si-DLC intermediate layers, and DLC film coating}

As the apparatus equipped with the pressure-gradient-type plasma source could not be used to form a Si-containing DLC film, a radio-frequency (RF) plasma CVD apparatus was used to coat the Si-DLC and DLC film, and tetramethylsilane gas was introduced during the Si-DLC film formation [2]. Nitriding and formation of the AIN film using RIP were performed following the same procedure as described in above. Thereafter, the processed sample was removed from the apparatus into the atmosphere, placed in the RF plasma CVD apparatus, and processing was performed, with target thicknesses of $0.17 \mu \mathrm{m}$ for the Si-DLC intermediate layer and $1.0 \mu \mathrm{m}$ for the DLC film. For comparison, samples with a Si-DLC intermediate layer and a DLC film formed directly on an untreated sample were also prepared.

\section{Evaluation of DLC/AIN/nitrided samples}

An elemental profile of the cross-section of the treated sample was obtained using glow discharge-optical emission spectroscopy (GD-OES). In addition, the Vickers hardness was measured for the nitrided sample, and the nanoindentation hardness was measured for the DLC-coated/nitrided sample. To evaluate the adhesion of the DLC film, a Rockwell indentation test was performed using A-scale loading a charge of $588.4 \mathrm{~N}$ with a diamond cone indenter. The adhesion was evaluated by examining the degree of cracking and peeling around the indentation after the test through elemental mapping using electron probe microanalysis (EPMA). The friction wear characteristics of the DLC film were measured using a ball-on-disk type friction wear tester. The tests were performed in the atmosphere using a $1 / 4$-inch $\mathrm{Al}_{2} \mathrm{O}_{3}$ ball as the counter material under following conditions: Wear distance of $100 \mathrm{~m}$, load of $1 \mathrm{~N}$, wear radius of $5 \mathrm{~mm}$, and rotation speed of $50 \mathrm{rpm}$. Examination of the wear track after the friction wear test, measurement of the surface morphology using a stylus-type roughness measuring device, and measurement of the friction coefficient $\mu$ were then performed.

\section{Results and Discussion}

\section{Nitriding and DLC film coating}

Figure 4 shows the appearance of the treated sample and presents the Rockwell indentation and surface hardness measurements. The nitrided sample was blackened; however, for the sample with the DLC film coating after nitriding, the black color became slightly reddish. The nitrided sample had a hardness of $305 \mathrm{HV}$, whereas that of the sample with the DLC film formed after nitriding was 10.3 GPa. The hardness of the untreated A5052 aluminum alloy sample was $125 \mathrm{HV}$, suggesting an improvement of the hardness compared with that of the base material. The DLC film was formed thereon. The DLC film could be coated at temperatures as low as $188^{\circ} \mathrm{C}$. No separation was observed between the base material and nitrided surface in the Rockwell indentation results, however, peeling was observed at the boundary and periphery of the indentation of the sample coated with the DLC film, indicating insufficient adhesion. The insufficient hardness of the nitrided layer ( $305 \mathrm{HV}$ ) is considered to be the cause of this poor adhesion.

Figure 5 presents the GD-OES elemental depth profiles of the nitrided sample and sample with DLC film coating after nitriding. In the nitrided sample (Figure 5a), nitrogen is observed up to a depth of 4-5 $\mu \mathrm{m}$, indicating progressive nitriding. However, in the surface region, the $\mathrm{N}$ concentration is larger than the Al concentration, suggesting a deviation from the stoichiometric composition of AIN. The shift of the calibration curve in the GD-OES measurement is considered to be cause of this this deviation. The Mg concentration was also confirmed in the nitrided layer. However, in the sample with the DLC film coating after nitriding (Figure 5b), C was detected in the surface region, indicating that a DLC film was formed. Moreover, $\mathrm{N}$ was detected in the surface layer, suggesting the formation of a $\mathrm{CN}$ film where $\mathrm{C}$ and $\mathrm{N}$ are present in a mixed state or that of an N-containing DLC film.

Next, friction and wear tests were performed on the DLC film. The wear track and the surface roughness measurements are shown in Figure 6. Al- 

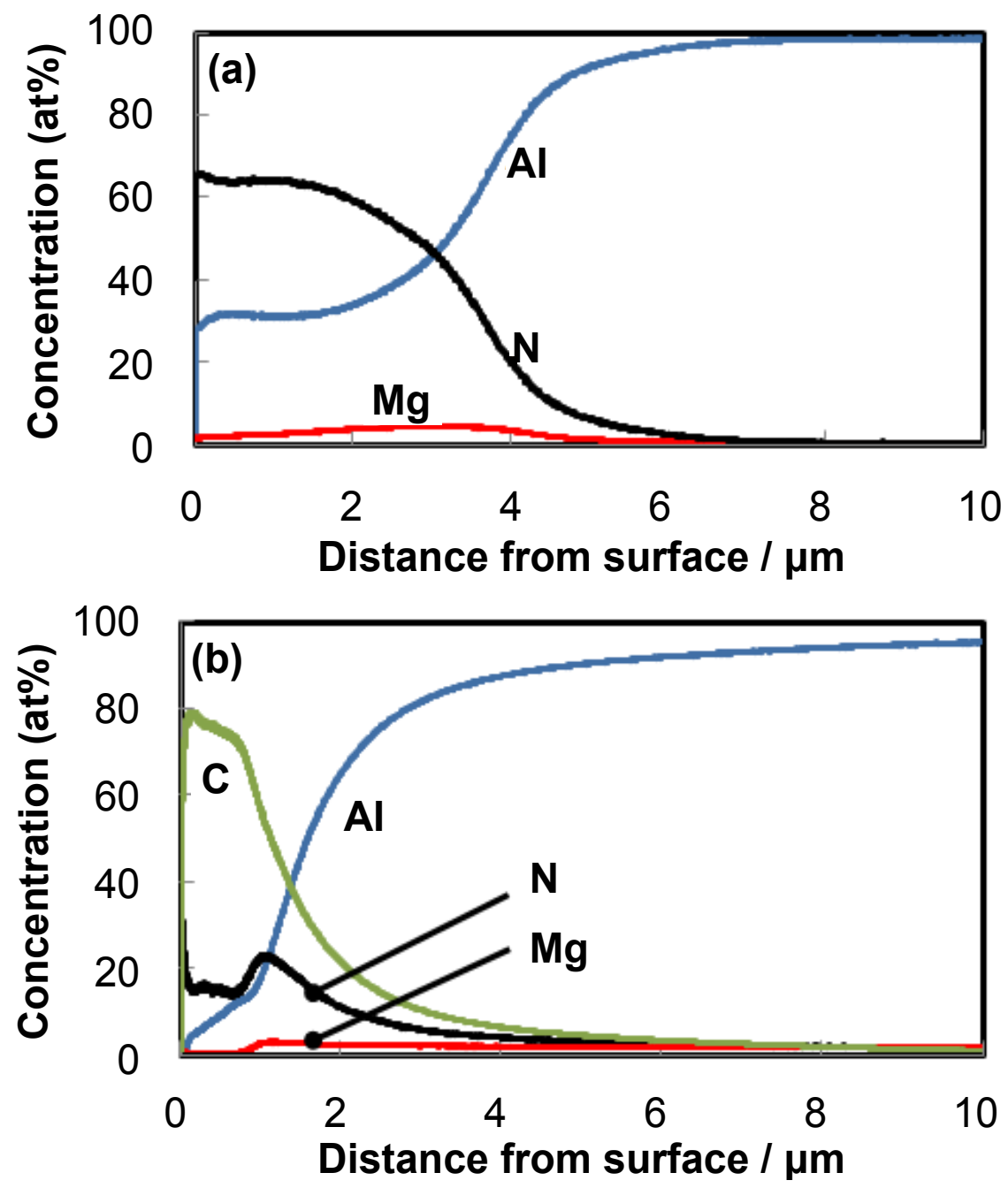

Figure 5: GD-OES elemental depth profiles of the: a) Nitrided sample; and b) Sample with DLC film coating after nitriding.

though abrasion marks were observed on the surface of the DLC film, the wear track was extremely small, and its position could not be specified in the cross-sectional profile. Furthermore, $\mu$ was 0.18 at the beginning of the friction test and 0.17 after 100 $\mathrm{m}$, indicating that the measurement values were stable. This superior friction resistance is reflective of the characteristics of a DLC film.

\section{Nitriding, AIN intermediate layer, and DLC film coating}

To improve the adhesion between the nitrided layer and the DLC film, an AIN film was formed as an intermediate layer using RIP. The thin, golden surface of the AIN film formed after nitriding is shown in Figure 7. The surface hardness increased to $638 \mathrm{HV}$ and the nanoindentation hardness was 11.4 GPa. In addition, the thickness of the AIN film was $3.4 \mu \mathrm{m}$, which demonstrates that high- speed film formation at low temperature is possible using RIP. For the Rockwell indentation test, some cracks and peeling were observed around the indentation; however, good adhesion was attained. A plausible reason for this good adhesion is that AIN formed by nitriding and that formed by RIP have the same elemental composition and the bondability to the interface is enhanced. Another factor to consider is that a harder AIN layer could be formed using RIP.

For the sample coated with the DLC film after forming the AIN intermediate layer, a black surface characteristic similar to those for the DLC film were observed. The nanoindentation hardness of the surface was $26.7 \mathrm{GPa}$. Figure 8 presents the EPMA results for the surface after the Rockwell indentation test. $\mathrm{Al}$ and $\mathrm{N}$ were detected around the indentation, suggesting a separation between the DLC film and AIN intermediate layer. Therefore, 


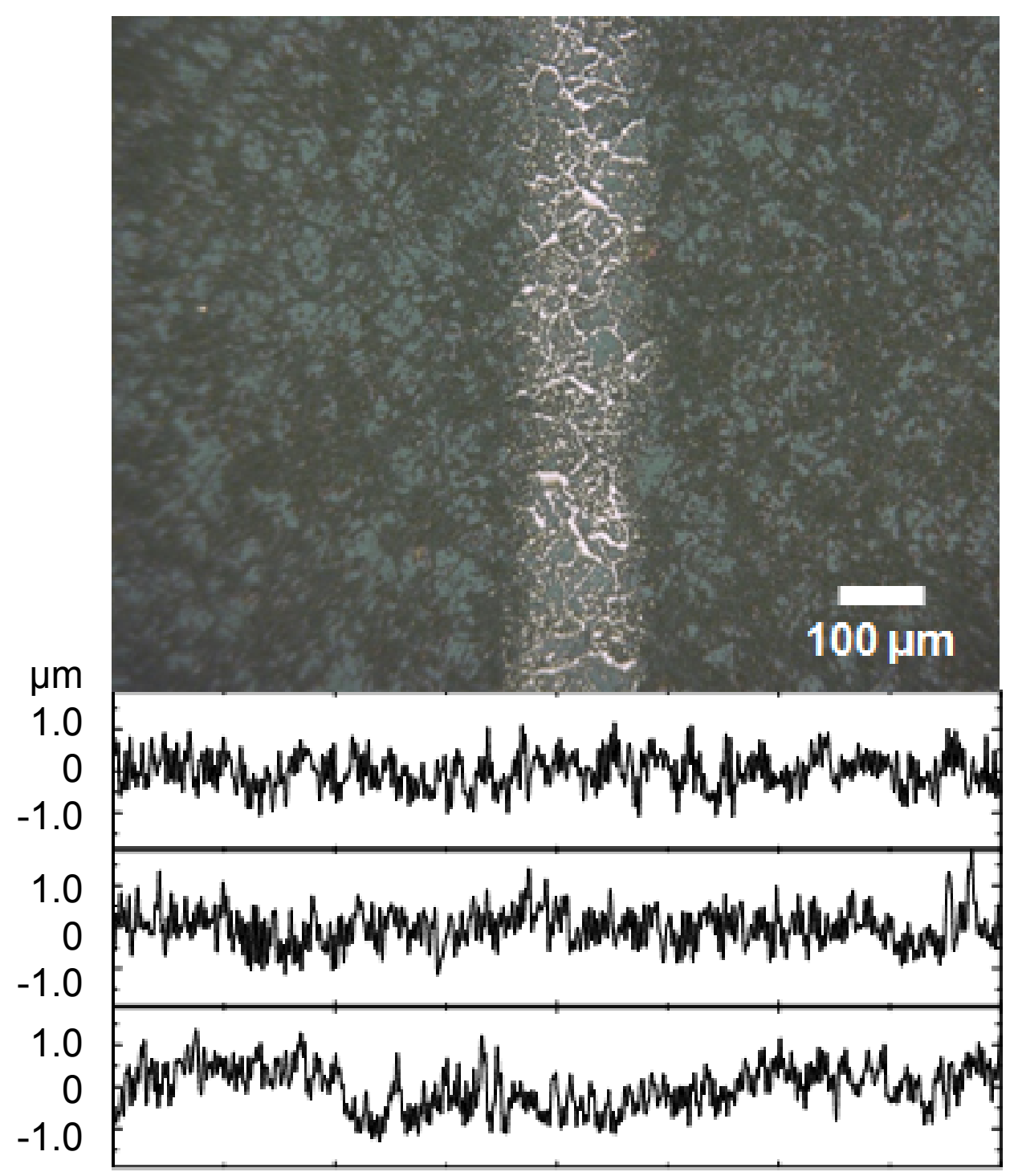

Figure 6: Wear track and surface roughness of the DLC film/nitrided layer sample after friction and wear test.

it was concluded that sufficient adhesion was not achieved by only forming the AIN intermediate layer via the RIP method and that separation occurred between the AIN and DLC films.

\section{Nitriding, AIN and Si-DLC intermediate layers, and DLC film coating}

Figure 9 shows the appearance of the sample after the treatment and presents the Rockwell indentation and nanoindentation surface hardness measurements. A glossy black color characteristic of DLC films was observed for all cases. The hardness was as high as $23.6-28.0 \mathrm{GPa}$ in all the samples. In the Rockwell indentation test, a small extent of peeling was observed around the indentation of the DLC film formed on the untreated sample. However, for the DLC film/SiDLC intermediate layer/AIN intermediate layer/ nitrided layer/base material sample, even though slight cracks and separation were observed for part of the indentation edge portion, good adhesion was attained. Figure 10 presents the EPMA results for the surface after the Rockwell indentation test. Al and $\mathrm{N}$ were detected at the indentation edge part of the sample of the DLC film/SiDLC intermediate layer/AIN intermediate layer/ nitrided layer/base material. Therefore, peeling of a portion between the AIN intermediate layer and Si-DLC intermediate layer can be inferred. In this study, the sample was removed and stored in the air atmosphere before coating the Si-DLC intermediate layer and DLC film, which may lead to a decrease in adhesion. Therefore, improvement in adhesion can be expected by consistently performing the treatment under vacuum in a future study. 


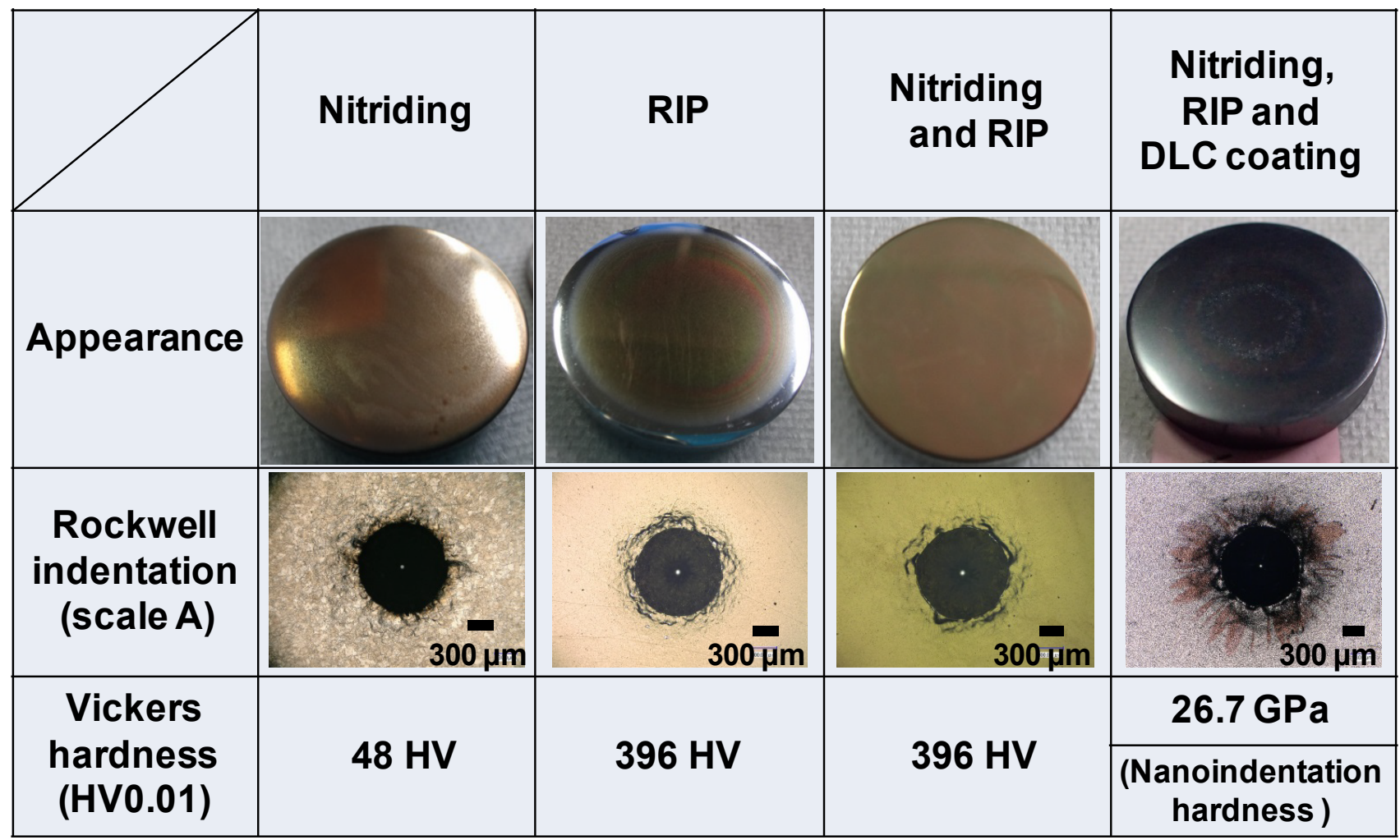

Figure 7: Appearance of samples, Rockwell indentation and surface hardness after nitriding, AIN intermediate layer, and DLC film coating.

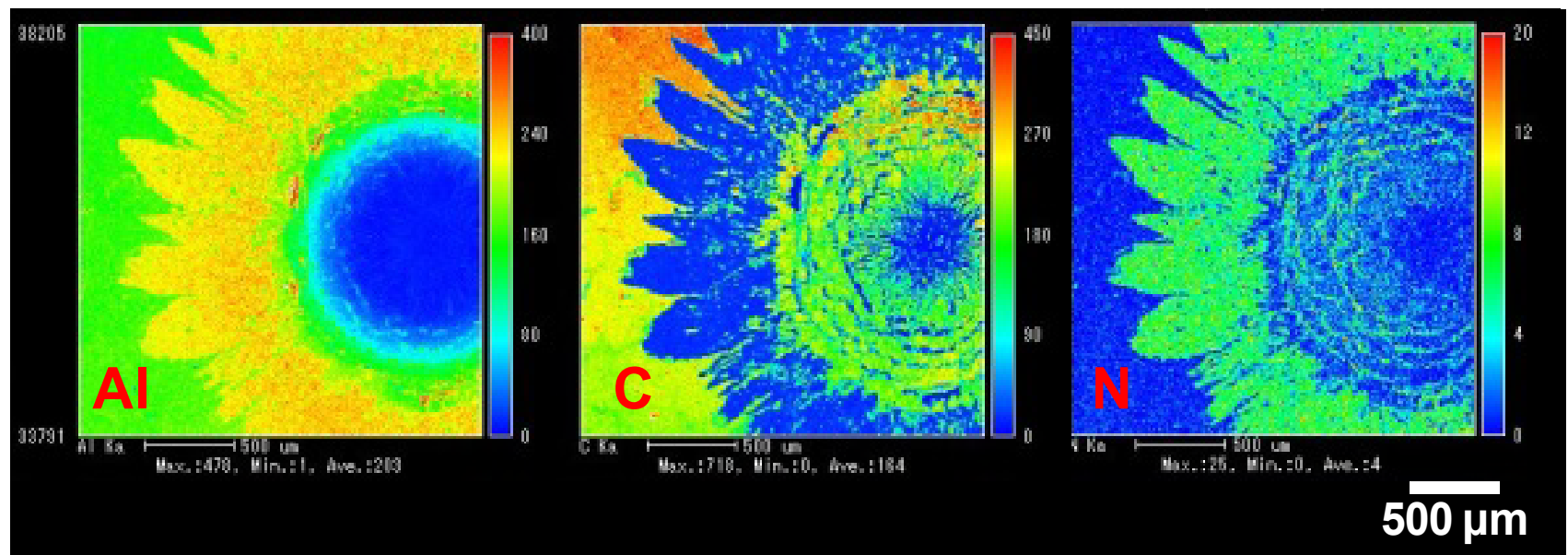

Figure 8: EPMA results for the DLC film/AIN intermediate layer sample surface after the Rockwell indentation test.

\section{Conclusions}

In this study, a DLC film and nitrided layer were deposited onto an aluminum alloy using a pressure-gradient-type plasma source with $\mathrm{N}_{2}$ and $\mathrm{C}_{2} \mathrm{H}_{2}$ gases. The Vickers microhardness of the surface nitrided at $0.51 \mathrm{~Pa}$ reached approximately 305 $\mathrm{HV}$ compared with an initial hardness of $101 \mathrm{HV}$ for the base material. In addition, GD-OES analysis revealed that nitrogen was concentrated in the surface region. The GD-OES results also demonstrated that after the DLC coating, a carbon-rich region formed at the top surface of the DLC film followed by the formation of a nitrided layer. Nanoindentation tests indicated that the hardness of the DLC film was $10.3 \mathrm{GPa}$. The DLC coating also exhibited good tribological performance in a ballon-disk wear test, with friction coefficients of approximately 0.17 , which is considered a low value 


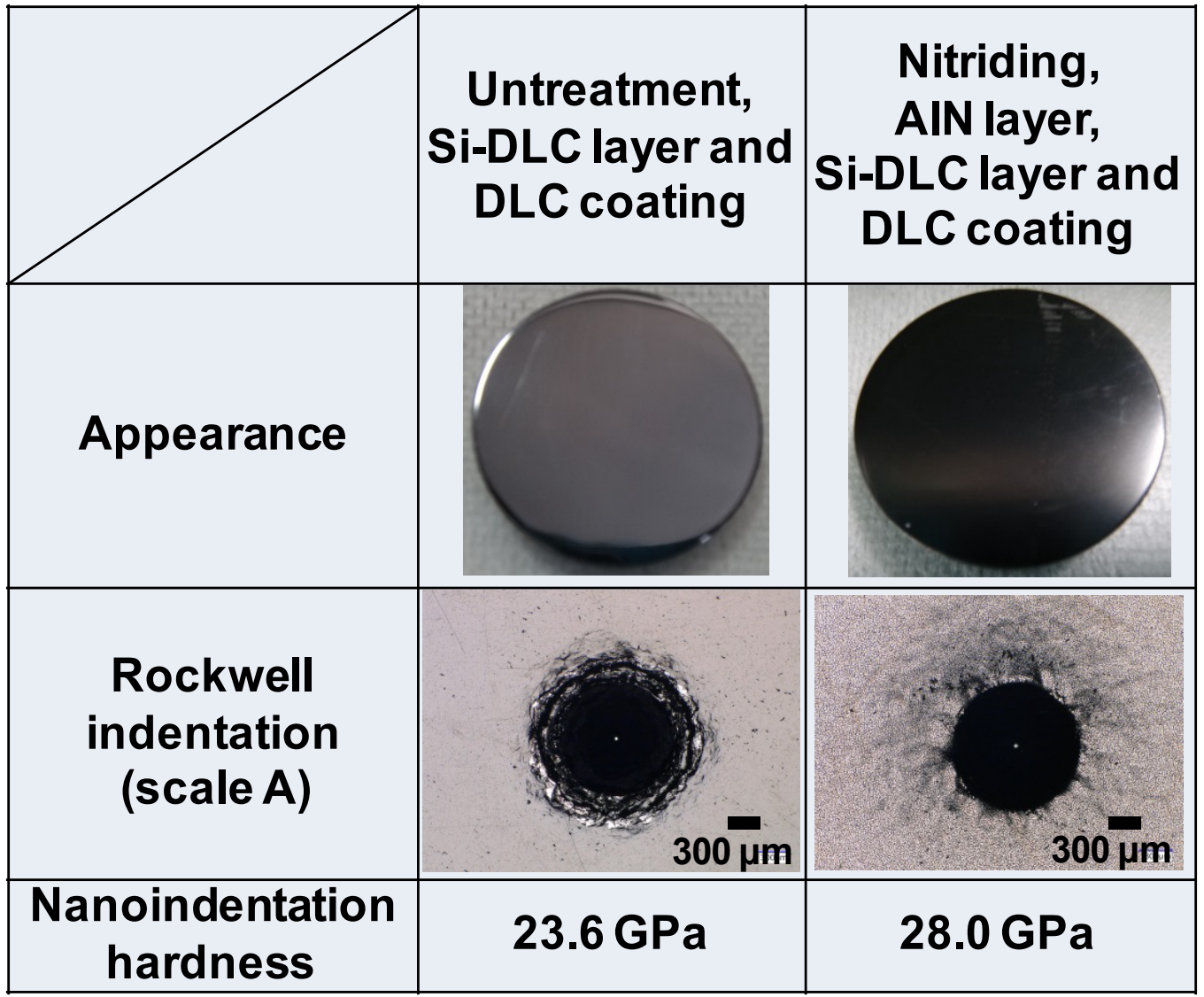

Figure 9: Appearance of samples, Rockwell indentation and surface hardness after nitriding, AIN and Si-DLC intermediate layers, and DLC film coating.

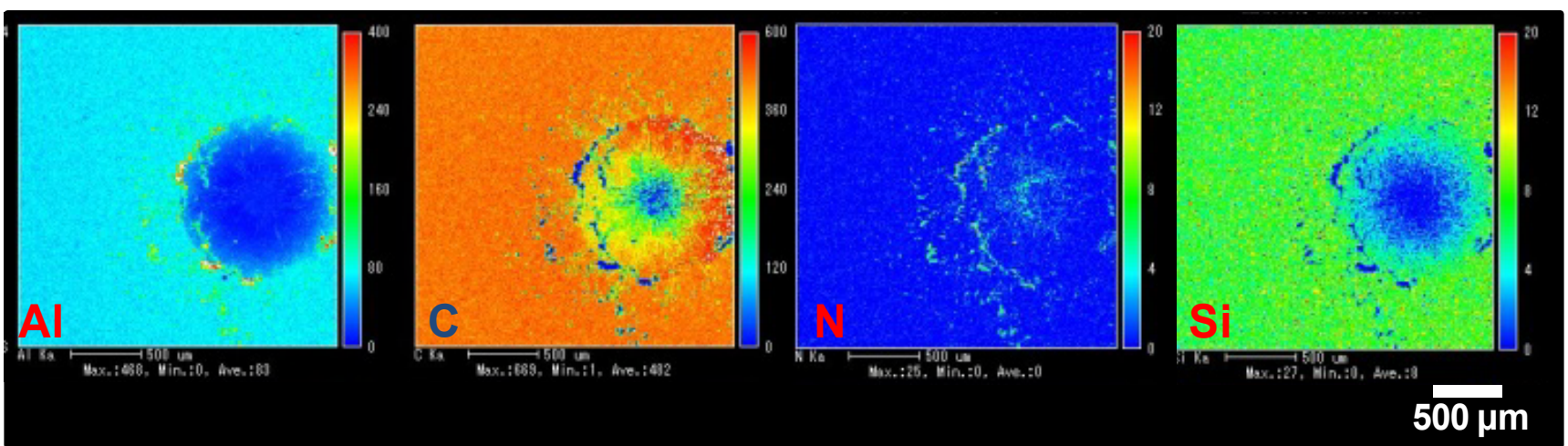

Figure 10: EPMA results for the DLC film/Si-DLC intermediate layer/AIN intermediate layer/nitrided layer sample surface after the Rockwell indentation test.

for DLC films. Moreover, the addition of another Si-containing DLC intermediate layer was shown to further improve the adhesion between the nitrided layer and DLC film.

\section{References}

1. L Wang, S Wan, SC Wang, RJK Wood, QJ Xue (2010) Gradient DLC-based nanocomposite coatings as a solution to improve tribological performance of aluminum alloy. Tribol Lett 38: 155-160.
2. H Maruno, A Nishimoto (2018) Adhesion and durability of multi-interlayered diamond-like carbon films deposited on aluminum alloy. Surf Coat Technol 354: 134-144.

3. E Furuya, K Kousaka, A Nishimoto (2015) Plasma nitriding of aluminum alloy using pressure-gradient-type plasma gun. Preprints of $80^{\text {th }}$ meeting of JSHT 80: 31-32.

4. M Nakamura, S Kubota, H Suzuki, T Haraguchi (2015) 
Wear and friction characteristics of AIN/diamond-like carbon hybrid coatings on aluminum alloy. J Mater Eng Perform 24: 3789-3797.

5. M Nakamura, Y Takamori (2016) Fatigue reliability evaluation of aluminium alloy coated with diamond-like carbon/AIN hybrid coatings by UBMS. Trans JSME 82: 16-00157.

6. P Visuttipitukul, T Aizawa, H Kuwahara (2003) Advanced plasma nitriding for aluminum and aluminum alloys. Mater Trans 44: 2695-2700.

7. P Visuttipitukul, T Aizawa (2005) Wear of plasma-nitrided aluminum alloys. Wear 259: 482-489.

8. M Moradshahi, T Tavakoli, S Amiri, Sh Shayeganmehr (2006) Plasma nitriding of Al alloys by DC glow discharge. Surf Coat Technol 201: 567-574.

9. G da Silva Savonova, MGG Camarinha, LO Rocha, MJR Barboza, GV Martins (2019) Study of the influence of the RRA thermal treatment and plasma nitriding on corrosion behavior of 7075-T6 aluminum alloy. Surf Coat Technol 374: 736-744.

10.X Li, W Xin, X Zheng, Z Ren, D Sun, W Lu (2019) Microstructural characterization and formation mech- anism of nitrided layers on aluminum substrates by thermal plasma nitriding. Metals 9: 523.

11.S Tatematsu, E Furuya, A Nishimoto (2014) High-vacuum based plasma nitriding using high-current hollow cathode discharge. Preprints of $78^{\text {th }}$ meeting of JSHT 78: 81-82.

12.E Furuya, K Kousaka, A Nishimoto (2015) High-concentrated plasma nitriding using high-current hollow cathode discharge. Preprints of $79^{\text {th }}$ meeting of JSHT 79: 33-34.

13.E Furuya, H Mizuno (2003) Handbook of ion engineering. Institute of Ion-Engineering, 266.

14.J Uramoto (1982) Research of high current and long life cathode for ion plating. J Vac Soc Jpn 25: 660670.

15. Y Takahashi, K Nitobe, J Uramoto, T Momose, H Ishimaru (1993) Aluminum oxide thin film deposition by reactive ion plating using the cathode system composed of $\mathrm{LaB}_{6}$ disc and Ta pipe. J Vac Sci Technol A 11: 1491-1495.

16.M Niiya, E Furuya, N Nakamura (1999) MgO coating apparatus for next generation type PDP. Electr Technol 41: 68-70. 